\title{
Potensi Pemanfaatan Serat Selulosa sebagai Material Bahan Baku dalam Sintesis Filter Udara Non-Woven sesuai Standar TAPPI T 205
}

\author{
Irwan Suriaman ${ }^{1, a, *}$, Mardiyati ${ }^{2}$, Jooned Hendrarsakti ${ }^{3}$ dan Ari Darmawan Pasek ${ }^{4}$ \\ ${ }^{1,2,3,4}$ Fakultas Teknik Mesin dan Dirgantara, Institut Teknologi Bandung, Indonesia \\ a Jurusan Teknik Mesin, STT Wastukancana, Purwakarta, Indonesia
}

1.*irwan@stt-wastukancana.ac.id, ${ }^{2}$ mardiyati@material.itb.ac.id, ${ }^{3}$ jooned@ftmd.itb.ac.id, ${ }^{4}$ aripasek@itb.ac.id,

\begin{abstract}
Industry 4.0 era materials used by entrepreneurs should be recycled, environmentally friendly, renewable with less chemical content. Indonesia as a tropical country has a large land area with the potential to produce the largest natural fiber in the world. One opportunity that can be applied to the utilization of natural fibers in air filters that currently use dominant materials is synthetic fibers. natural fiber has the advantage because it does not contain toxic chemicals, local raw materials, and is easily produced. This research will analyze the mechanical and morphological characteristics of biological fibers that have great potential as pre-filter raw material. Analysis of mechanical properties through tensile strength testing for single fibers and morphological analysis through scanning electron microscopy (SEM). Tensile testing was the results are; palm oil has a tensile strength of $620 \mathrm{MPa} ; 998 \mathrm{MPa}$ and $213 \mathrm{MPa}$ flax coconut fiber. For the morphological test results from SEM analysis for ramie fiber, it looks solid without fiber holes; The fibers appear to be many small fibers bound to one another while coir fibers have many pore holes in one observed fiber.
\end{abstract}

Kata kunci : Filter udara, serat hayati, serat sintetik, kekuatan tarik dan morpologi.

\section{Pendahuluan}

Pertumbuhan ekonomi dan jumlah penduduk akan berefek pada peningkatan polusi udara luar ruangan (ambient). Data dari Kementerian Lingkungan Hidup, 2017 polusi udara dari sektor transportasi sekitar $70 \%$ dan industri 20\% (Wang, 2016). Polusi udara terdiri dari gas $\left(\mathrm{CO}_{2}, \mathrm{SOx}, \mathrm{NOx}\right)$ dan partikel padat $\left(\mathrm{PM}_{10}\right.$ dan $\left.\mathrm{PM}_{2,5}\right)$. Peningkatan jumlah polusi udara ambient akan terjadi depresiasi kualitas udara dalam ruangan. Hal ini akan destruktif terhadap kesehatan dan produktifitas manusia (Fazlzadeh, 2015 dan Chen, 2015).

Derajat depresiasi kualitas udara dalam ruangan dapat dicegah secara mekanik dan konvensional (McGill, 2015). Metode mekanik melalui sistem filtrasi menggunakan air conditioning (AC) atau purifier, sedangkan mekanisme konvensional dengan menempatkan beberapa jenis tanaman yang dapat mengabsorpsi polutan yang terdapat dalam ruangan (Bennett, 2014). Implementasi sistem mekanik menggunakan peralatan dengan memerlukan sumber energi dalam operasional, metode konvensional tidak demikian. Untuk hasil dan kecepatan peningkatan indeks kualiats udara dalam ruangan metode mekanik lebih efektif dibandingkan dengan metode konvensional, hal ini karena metode mekanik kelajuan udara yang melewati sistem filtrasi lebih cepat dengan volume yang lebih banyak. Namun dengan metode konvensional terjadi depresiasi jumlah polutan melalui penyerapan pada bagian stomata tumbuhan akibat efek gravitasi dan massa partikel (Allen, 2009 dan Syafri, 2018).

Material filter pada sistem filtrasi udara sebagai mekanisme yang paling efektif, masih didominasi bahan polimer sintetik dari residu minyak bumi. Polimer merupakan material yang memiliki gugus fungsi yang berulang secara teratur, dipengaruhi oleh derajat polimerisasi (Pickering, 2005 dan Rameh, 2017). Bahan baku polimer sintetik banyak mengandung bahan kimia beracun, tidak mudah diproduksi dan pemicu penyakit kanker (Bao, 2016). Oleh karena itu ada potensi untuk mengganti material ini dari serat hayati yang banyak diproduksi di Indonesia.

Serat hayati merupakan polimer yang salah satunya berasal dari bahan selulosa yang mudah diproduksi serta berbahan baku lokal. Pada riset kali ini akan dianalisis sifat mekanik dan morpologi dari serat hayati yang menjadi faktor penting pertimbangan dalam pemilihan material pra filter udara untuk digunakan pada sistem filtrasi pada air conditioning (AC) agar indeks kualitas udara dalam ruangan dapat meningkat. Hal ini akan berefek positif bagi kesehatan hidup manusia. 


\section{Bahan dan Metode}

Serat hayati yang diujikan berasal dari tiga jenis tanaman pada Gambar 1 yaitu: ijuk (Arenga pinnata), rami (Beohmeria nivea) dan sabut kelapa (Cocos nucifera), serat ini berasal dari Kabupaten Garut, Jawa Barat, Indonesia. Serat ini diperoleh melalui dekortikasi dari bulu batang (ijuk), kulit batang (rami) dan kulit buah (sabut kelapa).
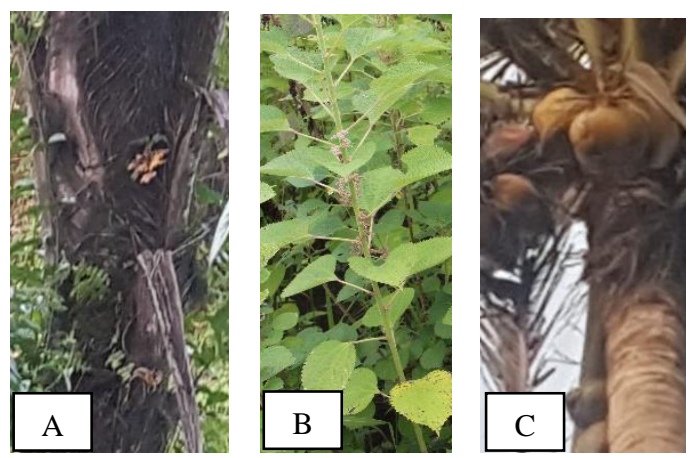

Gambar 1 Tanaman bahan baku serat hayati: (A) ijuk; (B) rami; (C) sabut kelapa.

Serat terdiri dari bahan baku seperti tampak pada Gambar 2 tanpa perlakuan dan perlakuan alkali 3\% menggunakan natrium hidroksida $(\mathrm{NaOH})$ pada suhu kamar, selama 6 jam. Serat kemudian dikeringkan secara alami dengan menggunakan sinar matahari sampai kadar air sekitar $10 \%$.
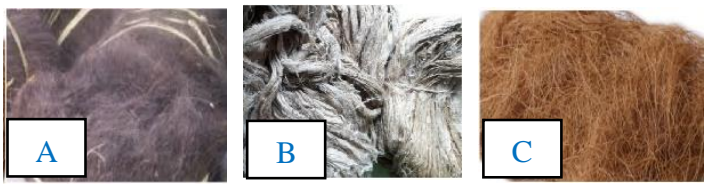

Gambar 2 Bahan baku serat hayati: (A) ijuk; (B) rami; (C) sabut kelapa.

Sifat mekanik diperoleh melalui pengujian kekuatan tarik (tensile strength) untuk serat tunggal dengan menggunakan mesin textechno favigraph yang dilakukan di BBTB, Jawa Barat, sesuai standar ASTM 3822. Serat yang diujikan pada rentang diameter $0.15-1.15 \mathrm{~mm}$. Pengujian dilakukan pada gauge length $5 \mathrm{~mm}$ dengan test speed $20 \mathrm{~mm} / \mathrm{min}$ pada kondisi suhu kamar sekitar temperature ruangan sekitar $26^{\circ} \mathrm{C}$ dengan RH 56.

Uji morpologi dilakukan melalui analisis scanning electron microscopic (SEM) dengan jenis JEOL JSM-6510, dilakukan di Balai Besar Tekstil Bandung, Jawa Barat. Setiap sampel terlebih dahulu dipotong kecil-kecil dengan ukuran sekitar $1 \mathrm{~cm}$, kemudian ditempatkan pada pelat aluminium untuk diberikan lapisan emas (Au) agar sampel yang diujikan dapat bermuatan dengan alat sputter coater JEOL JEC-3000FC.
Material pra filter udara diproduksi dari bahan baku serat hayati yang digunakan sesuai standar Technical Association of the Pulp and Paper Industry (TAPPI) T-200 dan T-205 diproduksi di laboratorium Kertas dan pulp ITSB, Cikarang, Jawa Barat. Lalu uji performa untuk material pra filter udara sesuai standar ASHRAE 52.2 untuk sistem filtrasi pada partikel PM 2,5 $\mu \mathrm{m}$, dilakukan di laboratorium fisika, ITB.

\section{Hasil dan Pembahasan}

Hasil uji kekuatan tarik serat hayati seperti tampak pada Gambar. 3 menunjukkan peningkatan secara signifikan setelah diberikan perlakuan alkali, ijuk sebelum alkali $435 \mathrm{MPa}$ menjadi $620 \mathrm{MPa}$, rami sebelum alkali $812 \mathrm{MPa}$ menjadi $998 \mathrm{MPa}$ dan sabut kelapa sebelum alkali $127 \mathrm{MPa}$ menjadi $213 \mathrm{MPa}$. Hal ini karena dengan perlakuan $\mathrm{NaOH}$ terjadi ikatan hidroksil antar elemen serat hayati baik gum dan unsur lignin dengan natrium hidrosida $(\mathrm{NaOH})$, lalu terlarut dalam air sehingga unsur selulosa dominan (Rowell, 2000).

Kenaikan kekuatan tarik yang terjadi setelah diberikan perlakuan alkali serat ijuk sekitar $41 \%$, rami $44 \%$ dan sabut kelapa $37 \%$. Terjadinya proses alkalisasi menyebabkan depresiasi kandungan gum dan lignin, sehingga kandungan selulosa lebih banyak, hal ini menyebabkan ikatan struktur pada serat menjadi lebih teratur yang berefek pada sifat kekuatan serat tarik meningkat (Taalah, 2014).

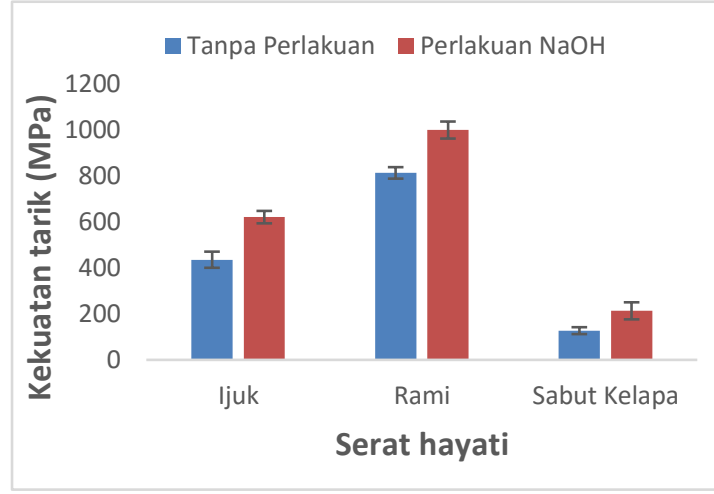

Gambar 3 Kekuatan tarik serat hayati; ijuk, rami dan sabut kelapa untuk kondisi tanpa perlakuan dan perlakuan alkali $(\mathrm{NaOH})$

Hasil uji SEM yang telah dilakukan untuk serat hayati tampak pada Gambar. 4 yang menunjukkan adanya perbedaan tanpa perlakuan lebih banyak kandungan gum dan lignin dibandingkan setelah perlakuan alkali (NaOH). Serat ijuk tampak microfibril terikat kuat satu sama lain tanpa ada pori Gambar 4, rami memiliki serat lebih padat dan kokoh sedangkan serat sabut kelapa tampak banyak terdapat pori-pori kecil pada microfibril dengan kekuatan yang kurang padat antar serat dengan ikatan yang terjadi satu sama lain (Shahinur, 2017). 
Tanpa Perlakuan

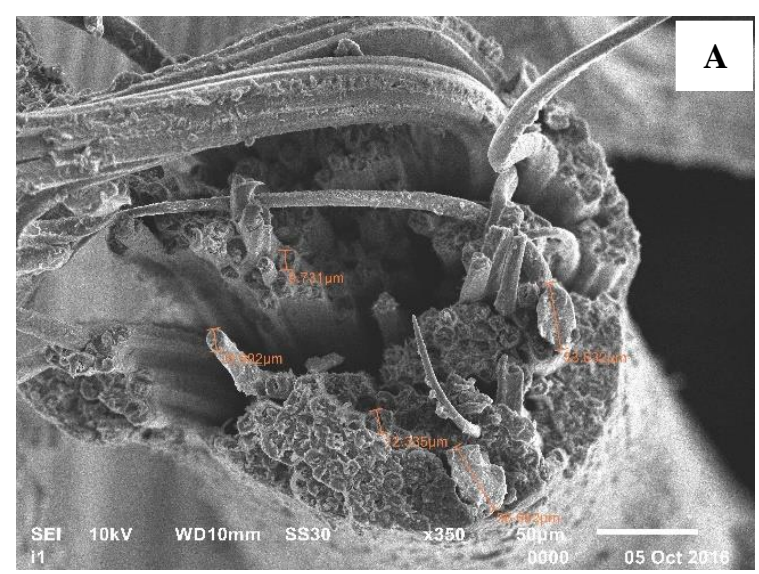

Perlakuan Alkali (NaOH)

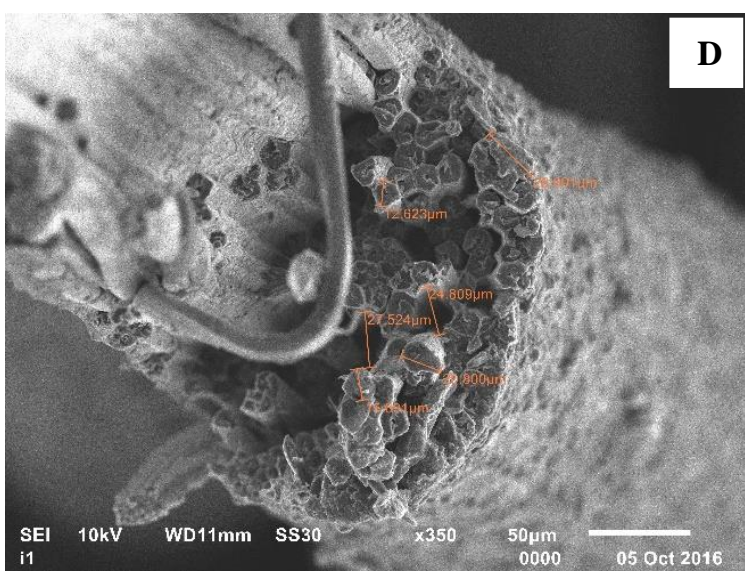

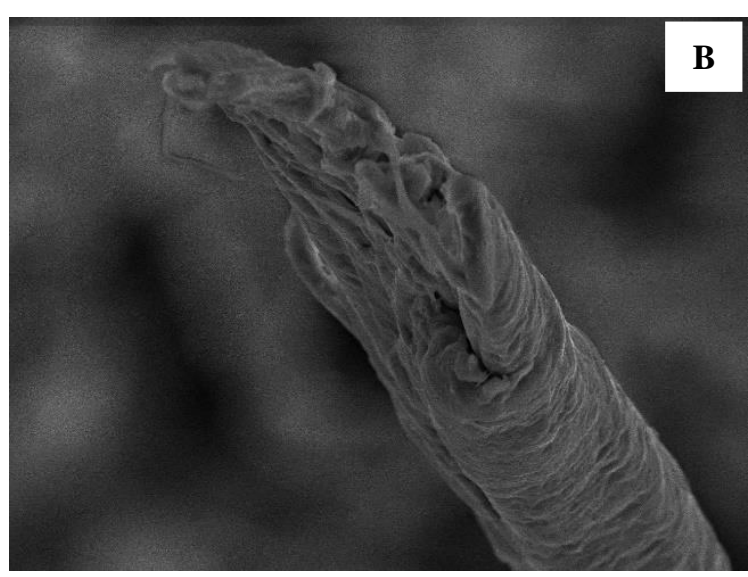
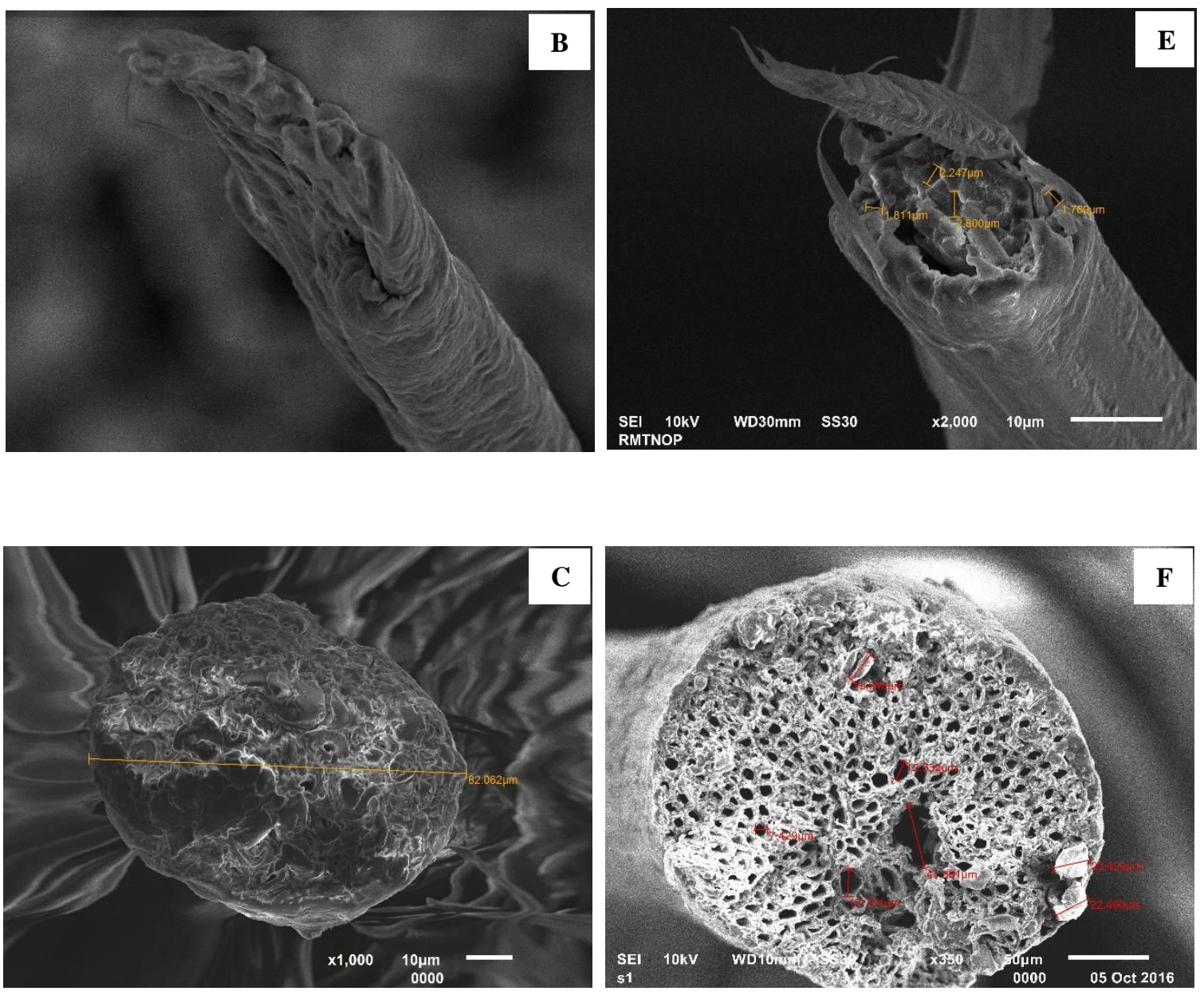

Gambar 4 Morpologi serat hayati dari hasil SEM sebelah kiri tanpa perlakuan: (A) ijuk; (B) rami dan (C) sabut dan sebelah kanan dengan perlakuan alkali $(\mathrm{NaOH})$ : (D) ijuk; (E) rami dan (F) sabut kelapa. 
Material filter udara telah diproduksi dari serat hayati berdasarkan standar TAPPI T-200 dan T-205. Tampak pada Gambar 5 proses pembuatan material filter yang dimulai dengan mesin beater (T-200) ditunjukkan Gambar 5(A) lalu dicetak dengan mesin handsheet (T-205) tampak pada Gambar 5(B). Serat hayati yang digunakan adalah serat rami perlakuan alkali 3\%, dengan pertimbangan memiliki kekuatan tarik terbaik diantara tiga serat yang diujikan, selain itu tampilan morpologi serat lebih padat dan kokoh (Angelini, 2013 dan Song, 2018).
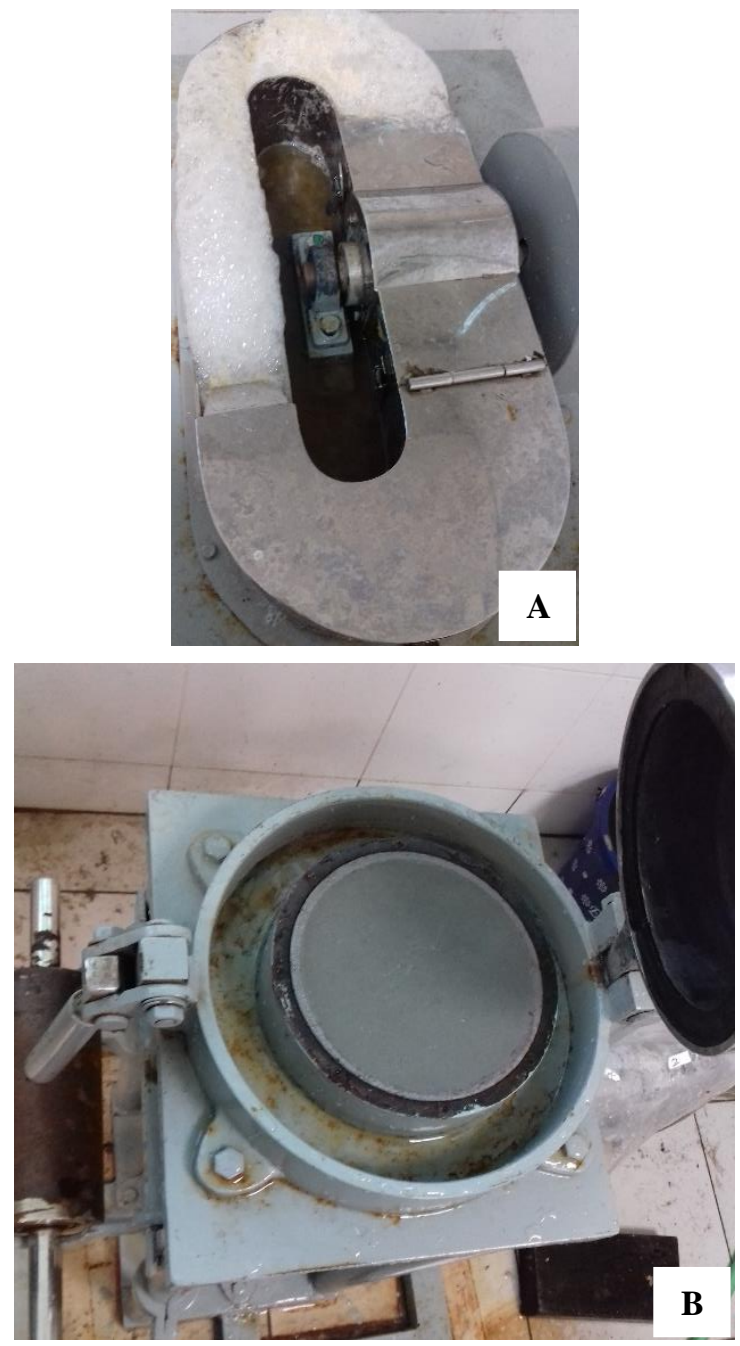

Gambar 5 Teknologi mesin produksi material filter udara sesuai standar TAPPI: (A) mesin beater (B) mesin handshett.

Materil filter udara yang sudah diproduksi tampak pada Gambar 6 kemudian telah diujikan performanya sesuai dengan standar ASHRAE 52.2. Untuk variabel penurunan tekanan (pressure drop) dan efisiensi filter udara. Penurunan tekanan tampak pada Gambar 7 tampak dari grafik pada gramatur yang berbeda 30,35 dan $40 \mathrm{~g} / \mathrm{m}^{2}$ cederung meningkat sebanding dengan peningkatan nilai gramatur dari filter udara.

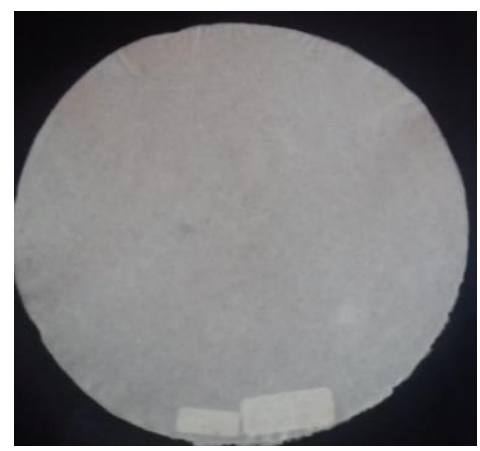

Gambar 6 Material filter udara yang diproduksi sesuai standar TAPPI, berbahan serat rami dengan perlakuan alkali $3 \%$.

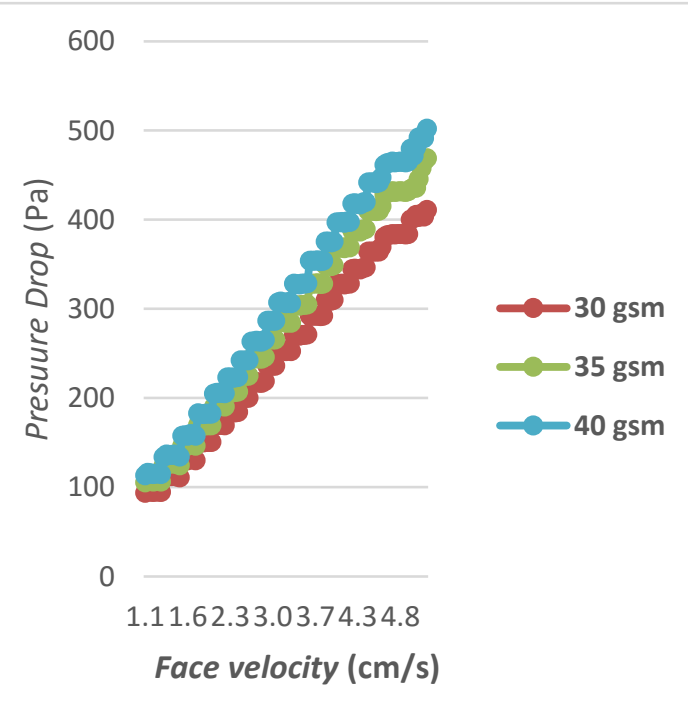

Gambar 7 Penurunan tekanan untuk material filter berbahan serat hayati untuk gramatur 30,35 dan $40 \mathrm{~g} / \mathrm{m}^{2}$.

Hasil pengujian untuk efisiensi filter udara ditunjukan pada Gambar 8, dengan peningkatan gramatur dari filter udara, maka efisiensi juga akan semakin meningkat. Hal ini karena kerapatan dari material filter semakin baik, namun penurunan tekanan yang terjadi juga semakin besar akibat poripori semakin mengecil (Bennet, 2014).

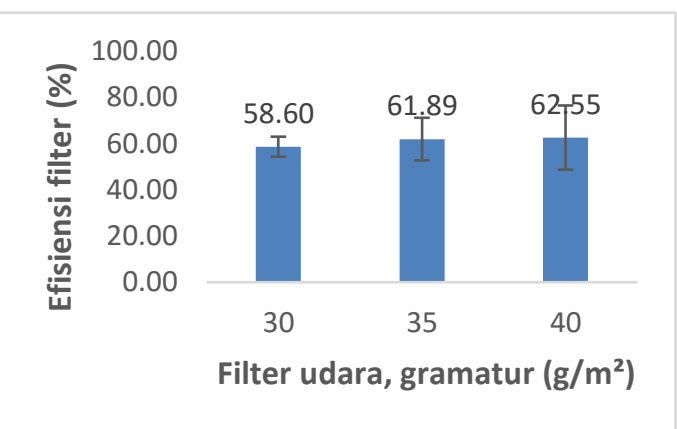

Gambar 8 Efisiensi filter udara berbahan serat hayati untuk gramatur 30,35 dan $40 \mathrm{~g} / \mathrm{m}^{2}$. 


\section{Kesimpulan dan Saran}

Serat hayati berdasarkan hasil data pengujian sifat mekanik dan morpologi diperoleh bahwa, polimer hayati sangat potensial untuk dijadikan material pra filter udara. Alasan lain adalah potensinya untuk menggantikan material saat ini yang berasal dari polimer sintetik karena sintetik memiliki kekurangan terutama berbahaya bagi kesehatan.

Hasil uji kekuatan tarik tertinggi adalah serat rami setelah diberikan alkali 3\% sekitar $998 \mathrm{MPa}$ yang didukung dengan hasil uji morpologi tampak bahwa serat rami lebih padat ikatan antar elemen dan tidak memiliki pori-pori microfibril. Selain itu hasil uji performa filter dari serat hayati mampu menyaring partikel udara untuk ukuran PM 2,5 $\mu \mathrm{m}$ walaupun masih memiliki kekurangan karena memiliki pressure drop yang tinggi.

Pada riset ini penulis menyarankan untuk memberikan perhatian yang serius dari seluruh pihak, baik institusi pendidikan, pemerintah serta industri terkait kelayakan polimer hayati untuk digunakan sebagai pengganti pada material filter udara, dengan melakukan penelitian agar kualitas filter udara betul-betul siap untuk memasuki pasar konsumen karena memiliki banyak keunggulan dibandingkan polimer sintetik yang saat ini dominan digunakan di dunia air conditioning (AC).

\section{Ucapan Terima kasih}

Pada kesempatan ini ucapan terima kasih dan penghargaan yang sebesar-besarnya kepada Kementerian Riset dan Teknologi melalui program Beasiswa Unggulan Dosen Indonesia Dalam Negeri (BUDI-DN) yang bekerja sama dengan Lembaga Pengelola Dana Pendidikan (LPDP) yang telah memberikan beasiswa selama menempuh pendidikan program Doktor di Institut Teknologi Bandung (ITB). Rektor ITSB yang telah memberikan kesempatan untuk melakukan riset di laboratorium kertas dan pulp.

\section{Daftar Pustaka:}

Allen, R. W., Leckie, S., Millar, G., dan Brauer, M. (2009). The impact of lwood stove technology upgrades on indoor residential air quality. Atmospheric Environment, (43) 37, 5908-5915.

Angelini, L. G., dan Tavarini, S. (2013). Ramie (Boehmeria nivea Gaud.) as a potential new fibre crop for the Mediterranean region: Growth, crop yield and fibre quality in a long-term field experiment in Central Italy. Industrial Crops \& Products, 51, 138-144.

Bao, T., Chen, T., Wille, M. L., Ahmadi, N. E., Rathnayake, S. I., Chen, D., dan Frost, R. (2016). Synthesis, application and evaluation of non-sintered zeolite porous filter (ZPF) as novel filter media in biological aerated filters (BAFs). Journal of Environmental Chemical Engineering, (4) 3, 33743384.

Bennett, A. (2014). Industrial air filtration: Innovations in air filtration technology. Filtration and Separation, 51(4), 30-35.

Chen, C. H., Chan, C. C., Chen, B. Y., Cheng, T. J., dan Leon Guo, Y. (2015). Effects of particulate air pollution and ozone on lung function in nonasthmatic children. Environmental Research, 137, 40-48.

Fazlzadeh, M., Rostami, R., Hazrati, S., dan Rastgu, A. (2015). Concentrations of carbon monoxide in indoor and outdoor air of Ghalyun cafes. Atmospheric Pollution Research, (6) 4, 550555.

McGill, G., Oyedele, L. O., dan McAllister, K. (2015). Case study investigation of indoor air quality in mechanically ventilated and naturally ventilated UK social housing. International Journal of Sustainable Built Environment, (4) 1, 58-77.

Pickering, K. L., Efendy, M. G. A., dan Le, T. M. (2015). A review of recent developments in natural fibre composites and their mechanical performance. Composites Part A: Applied Science and Manufacturing, 83, 98-112.

Ramesh, M., Palanikumar, K., dan Reddy, K. H. (2017). Plant fibre based bio-composites: Sustainable and renewable green materials. Renewable and Sustainable Energy Reviews, 79(April 2016), 558-584.

Rowell, R. M., Han, J. S., dan Rowell, J. S. (2000). Characterization and Factors Effecting Fiber Properties. Natural Polymers an Agrofibers Composites, 115-134.

Shahinur, S., dan Sharif, A. M. M. (2017). Quantifying the uncertainty associated with the material properties of a natural fiber. Procedia CIRP, 61, 541-546.

Song, Y., dkk. (2018). Industrial Crops \& Products Short communication A green degumming process of ramie. Industrial Crops \& Products, 120(308), 131-134.

Syafri, E., Kasim, A., Abral, H., Tj, G., Sanjay, M. R., dan Herlina, N. (2018). International Journal of Biological Macromolecules Synthesis and characterization of cellulose nano fi bers (CNF) ramie reinforced cassava starch hybrid composites. International Journal of Biological Macromolecules, 120, 578-586.

Taalah B., Guettala A., Guetala S., dan Kriker A., (2014), "Mechanical properties and hygroscopicity behavior of compressed earth block filled by date palm fibers". Conbuildmat, pp. 161168.

Wang, I. J., Tung, T. H., Tang, C. S., dan Zhao, Z. H. (2016). Allergens, air pollutants, and childhood allergic diseases. International Journal of Hygiene and Environmental Health, 219(1), 66-71679 
